International Journal of Pharmaceutics \& Pharmacology

Available Online: https://ijpp.edwiserinternational.com

\title{
Solubility Enhancement of Diclofenac Using Solid Dispersions
}

\author{
Vivek Kumar Yadav, Pooja Jain, Thomson Santosh Alex, Mohd. Aamir Mirza* and Zeenat Iqbal* \\ Department of Pharmaceutics, School of Pharmaceutical Education and Research, Jamia Hamdard, New Delhi, India
}

Article info

Received 30 April 2021

Revised 01 June 2021

Available Online 15 June 2021

*Corresponding author: Dr. Mohd. Aamir Mirza and Dr. Zeenat Iqbal, Nano-formulation Research lab, Department of Pharmaceutics, School of Pharmaceutical Education and Research, Jamia Hamdard, New Delhi- 110062, India

\begin{abstract}
Background: The phenomenon which gives rise to a homogenous system, formed by the dissolution of solute in a solvent is known as solubility. Low solubility is the limiting factor in formulation development. Diclofenac being BCS class II drug have low aqueous solubility of $0.00401 \mathrm{mg} / \mathrm{ml}$. Amongst various solubility enhancement techniques, solid dispersion is the easiest one.

Objective: Present work is primarily focused on the development of solid dispersions of diclofenac through solvent evaporation technique utilizing Eudragit E100 as a carrier.

Methods: Solid dispersion consists of at least one active pharmaceutical ingredient as a carrier in solid state. Various methods for preparing solid dispersions includes melt extrusion, fusion lyophilization, spray drying, solvent evaporation, and super critical fluid (SCF) technology. Solvent evaporation technique is used among various solid dispersion methods.

Conclusion: The enhanced solubility found to be $0.485 \mathrm{mg} / \mathrm{ml}$. The dissolution was performed using USP Type II apparatus was \%CDR of pure drug and its solid dispersion in $8 \mathrm{hr}$ were found out to be $45.14926 \%$ and $98.04758 \%$ respectively. Henceforth, solid dispersion technique results marked solubility enhancement of diclofenac sodium.
\end{abstract}

Keywords: Solid dispersion; Diclofenac; Eudragit E100; Solvent evaporation; Solubility; Dissolution; Bioavailability

\section{Introduction}

Solubility is a critical parameter for achieving desired concentration in a systemic circulation by the homogenous dissolution of the solute in a suitable solvent for attaining required pharmacological response [1]. The major issue with the development of drug formulation is the low solubility of the drug. Only $50 \%-$ $60 \%$ of new chemical entities (NCEs) develop in industry are soluble in water rest are partially insoluble in water. The enhancement of solubility and bioavailability of low aqueous soluble drug is one of the most challenging aspects for drug development [2].

Diclofenac belongs to phenylacetic acid class and is a nonsteroidal anti-inflammatory drug (NSAIDs) having analgesic, anti-inflammatory and antipyretic actions. It was introduced in 1973 and belong to BCS class II with high permeability and low solubility. Various formulation consisting of diclofenac has been developed for increasing patient adherence and efficacy. Controlled release formulation of diclofenac sodium was developed with a goal of improvement in the safety profile, patient adherence and one daily dosage regimen in chronic pain patients [3]. It is sparingly soluble in water, acetic acid and glacial acetic acid; partially insoluble in chloroform, toluene and ether; soluble in ethanol and freely soluble in methanol [4]. 
Formulating a poorly water-soluble drug for oral route is always a challenge for scientists. There are many techniques such as particle size reduction (micronization and nanonization) modification of crystal habit can be done by manipulating crystalline state of the drug, drug dispersion can be made by formulating a eutectic mixture, using complexing agents complexation can be done, solid solution or solid dispersion, self-emulsifying drug delivery system and surfactants are used for the solubilization for formation of nano/micro-emulsion [5].

Formulating surface solid dispersion helps in reduction of agglomeration of the drug due to increase in surface area which further increases dissolution rate [6]. This technique can be achieved through incorporation of drug into a hydrophilic carrier system and further the subsequent deposition of the drug solution onto the adsorbent materials [7-10].

The aim of our work is to determine the extent of solubility enhancement in individual carrier in different proportion and to formulate a solid dispersion of diclofenac sodium.

\section{Materials and Method}

\section{Materials}

Drug diclofenac was received as a gift sample from Yarrow Chem, Pharmaceutical Lab, Mumbai, Maharashtra; Eudragit E-100, Sodium hydroxide and Anhydrous potassium dihydrogen orthophosphate were procured from Loba Chemie, Mumbai, Yarrow Chem, Mumbai and Central drug house, New Delhi respectively. Solvents like methanol and hydrochloric acid were supplied by Renkem, New Delhi.

\section{Methodology}

\section{Solubility study of Diclofenac in water}

Diclofenac solubility was measured in water by UV visible spectrophotometric method. Excess amount of Diclofenac was added in beaker containing fixed volume of water and is placed in magnetic stirrer for $24 \mathrm{hrs}$. After $24 \mathrm{hrs}$ the solution was filtered, dilution of filtrate was done using water and was analysed by spectrophotometer at $276 \mathrm{~nm}$ [11-16].

\section{Preparation of Solid Dispersion}

Solvent evaporation method was employed for solid dispersion of diclofenac sodium. Weighed amount of diclofenac sodium and Eudragit E-100 in various drugto-polymer ratio $\left(S_{1}=1: 1, S_{2}=1: 2, S_{3}=1: 3\right)$ were dissolved in sufficient amount of methanol. The solution was stirred manually on water bath and solvent was evaporated. Residues were dried in a desiccator up to 24 hours. The obtained product was triturated in mortar and pestle after which it was passed through sieve number 80 and stored in a closed [17-21].

\section{Evaluation of prepared solid dispersion}

\section{Percentage yield}

For determining the efficiency of the method used the percentage yield of solid dispersion was calculated. For calculating the percentage yield, total weight of the solid dispersion is determined, and yield is calculated by the following formula [22].

$$
\begin{aligned}
& \text { Percentage yeild } \\
& =\text { Initial weight of the drug and carrier } \\
& \text { /weight of the solid dispersion } \times 100
\end{aligned}
$$

\section{Determination of drug content}

For determination of drug content of the solid dispersion triplicate manner was employed. From each batch10mg of solid dispersion were taken and separately placed in $100 \mathrm{ml}$ of volumetric flask and dissolved in water and volume was make up to $100 \mathrm{ml}$. The absorbance was noted using UV spectrophotometry at $276 \mathrm{~nm}$ [17].

\section{Solubility studies}

Aqueous solubility of solid dispersion was measured using UV visible spectrophotometer in triplicate manner. Excess amount of the prepared solid dispersion was introduced in the beaker containing fixed volume of water and is placed in magnetic stirrer at $300 \pm 5 \mathrm{rpm}$ for 24 hours. After 24 hours the solution was filtered, diluted and then analysed spectrophotometrically at 276 $\mathrm{nm}[17,23,24]$.

\section{In-vitro drug release}

\section{Preparation of 0.1N HCL}

$8.3 \mathrm{ml}$ of concentrated $\mathrm{HCl}$ was taken and dissolved in $1000 \mathrm{ml}$ of water [25].

\section{Preparation of pH 7.4 phosphate buffer}

$1.36 \mathrm{~g}$ of potassium dihydrogen orthophosphate anhydrous and $0.4 \mathrm{~g}$ of $\mathrm{NaOH}$ was dissolved in $50 \mathrm{ml}$ water in different volumetric flask. Then, $50 \mathrm{ml}$ of potassium dihydrogen orthophosphate anhydrous solution was added into $39 \mathrm{ml}$ of $\mathrm{NaOH}$ solution in a volumetric flask and volume was made up to $1000 \mathrm{ml}$ [25].

\section{Dissolution}

The dissolution study of solid dispersion was performed using USP II dissolution test apparatus. Conditions were kept constant for all dissolution studies having the volume of media $900 \mathrm{ml}$ with a stirring speed of $50 \mathrm{rpm}$ and the temperature of the medium was maintained at 
$37 \pm 0.5^{\circ} \mathrm{C}$. For evaluating the drug release $0.1 \mathrm{~N} \mathrm{HCl}$ was employed. Later release studies were carried out in phosphate buffer solution of $\mathrm{pH} 7.4 .5 \mathrm{ml}$ of sample was withdrawn and transferred into $5 \mathrm{ml}$ fresh media after an interval of 30 minutes. Diclofenac concentration was determined by UV spectrophotometer at a wavelength $276 \mathrm{~nm}$. The percent cumulative drug release at different time intervals was further calculated [17,2630].

\section{Kinetics modelling of drug release}

For evaluating the mechanism of drug release from the solid dispersion the dissolution data was fitted in kinetic models. The release kinetics were analysed via linear regression analysis using mathematical models of zeroorder kinetics, Higuchi diffusion model and Korsmeyer Peppas kinetic model [31,32].

\section{Result and Discussion}

\section{Solubility of diclofenac in water}

The water-solubility of diclofenac was found to be $0.00401 \mathrm{mg} / \mathrm{ml}$ whereas the reported solubility of Diclofenac is $0.00482 \mathrm{mg} / \mathrm{ml}$.

\section{Evaluation of solid dispersion}

\section{Percentage yield}

Percentage yield was checked expressed on the basis of dry weight of drug and the carrier. It was noted that the yield of solid dispersion ranged between $57.9-61.1 \%$ (Table 1) [30,33].

Table 1: Percentage yield.

\begin{tabular}{|c|c|c|}
\hline $\begin{array}{c}\text { S. } \\
\text { No. }\end{array}$ & Formulation & $\begin{array}{c}\text { Percentage yield } \\
\text { Mean } \pm \text { SD } \\
(\mathbf{n}=3)\end{array}$ \\
\hline 1. & $\mathrm{~S}_{1}(1: 1)$ & $61.1 \pm 1.314$ \\
\hline 2. & $\mathrm{~S}_{2}(1: 2)$ & $59.8 \pm 1.758$ \\
\hline 3. & $\mathrm{~S}_{3}(1: 3)$ & $57.9 \pm 2.164$ \\
\hline
\end{tabular}

\section{Determination of drug content}

The drug content of the formulated solid dispersion was observed ranging between $26.6-87.92 \%$ as shown in the Table 2 [34].
Table 2: Percentage drug content.

\begin{tabular}{|c|c|c|}
\hline $\begin{array}{c}\text { S. } \\
\text { No }\end{array}$ & Formulation & $\begin{array}{c}\text { \% Drug content } \\
\text { Mean } \pm \text { SD } \\
(\mathbf{n}=\mathbf{3})\end{array}$ \\
\hline 1. & $\mathrm{~S}_{1}(1: 1)$ & $87.92 \pm 5.269$ \\
\hline 2. & $\mathrm{~S}_{2}(1: 2)$ & $64.56 \pm 7.953$ \\
\hline 3. & $\mathrm{~S}_{3}(1: 3)$ & $26.6 \pm 12.418$ \\
\hline
\end{tabular}

\section{Determination of solubility of solid dispersion}

The results of the solubility test on S1, S2 and S3 observed in distilled water were $0.485,0.2186,0.1748$ respectively as shown in table 3 . It was noted that the solubility of the prepared solid dispersion decreased as the ratio of carrier increases [35-37].

Table 3: Solubility of solid dispersion.

\begin{tabular}{|c|c|c|}
\hline $\begin{array}{c}\text { S. } \\
\text { No }\end{array}$ & Formulation & $\begin{array}{c}\text { Solubility }(\mathbf{m g} / \mathbf{m l}) \\
\text { Mean } \pm \text { SD } \\
(\mathbf{n}=\mathbf{3})\end{array}$ \\
\hline 1. & $\mathrm{~S}_{1}(1: 1)$ & $0.485 \pm 0.137$ \\
\hline 2. & $\mathrm{~S}_{2}(1: 2)$ & $0.2186 \pm 0.291$ \\
\hline 3. & $\mathrm{~S}_{3}(1: 3)$ & $0.1748 \pm 0.174$ \\
\hline
\end{tabular}

\section{In-vitro drug release profile}

The release of drug from solid dispersion $\left(\mathrm{S}_{1}\right)$ and its pure form was studied and it was noted that the drug release from solid dispersion was swift as contrast to its pure form because of the enhanced solubility in solid dispersion which enhances the dissolution rate. The drug releases from solid dispersion and its pure from is almost same in acidic media but drug releases in phosphate buffer was faster than its pure form. More than $90 \%$ of drug releases in phosphate buffer $\mathrm{pH} 7.4$ as shown in Figure 1. 
Citation: Yadav VK, Jain P, Alex TS, et al. Solubility Enhancement of Diclofenac Using Solid Dispersions. Int J Pharm Pharmacol 2021; 5: 154. doi: 10.31531/2581-3080.1000154

\section{$\%$ Drug release}

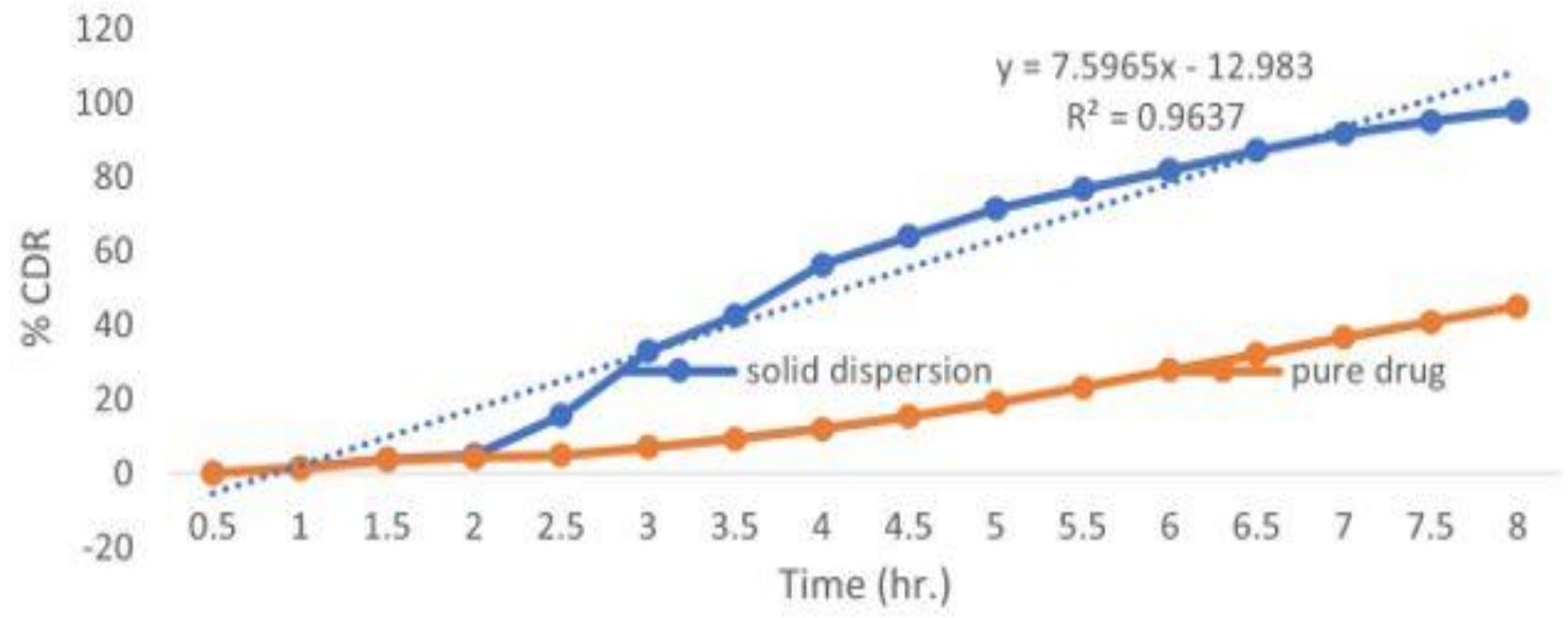

Figure 1: Comparison of in-vitro release of drug from its pure form and its solid dispersion.

\section{Drug release kinetics from solid dispersion}

For interpreting the release kinetics and mechanism of the drug release from SD mathematical model for drug release were used and it was found that the release was zero-order as shown in Figure 2.

\section{Release kinetics}

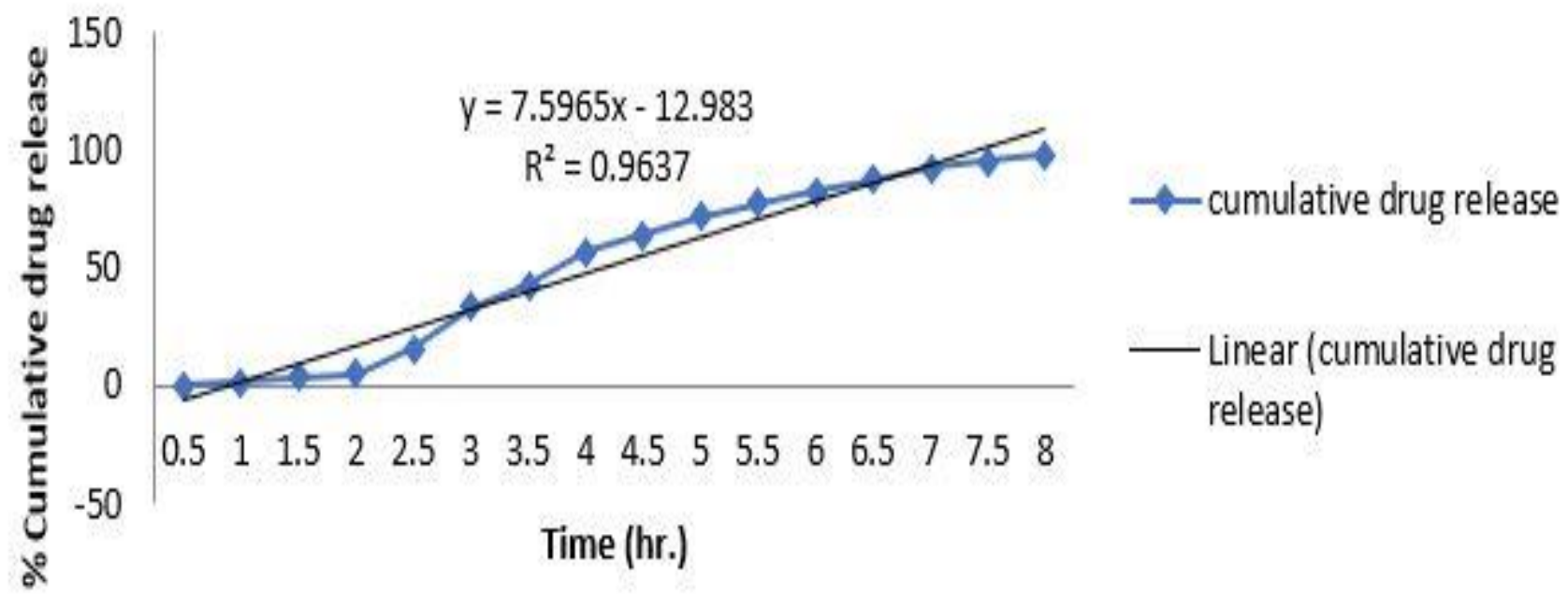

Figure 2: Drug release kinetics model from solid dispersion. 


\section{Conclusion}

Diclofenac was chosen as a drug for its solubility enhancement. Diclofenac is a BCS class II drug having low aqueous solubility. The observed solubility of diclofenac in water is $0.00401 \mathrm{mg} / \mathrm{ml}$ and reported was $0.00482 \mathrm{mg} / \mathrm{ml}$ at $276 \mathrm{~nm}$. For enhancing the solubility of drug solid dispersions were made using eudragitE100 (carrier) in various ratio $(1: 1,1: 2,1: 3)$. Prepared solid dispersions were evaluated for various parameters. Solid dispersions with drug: carrier 1:1 $\left(\mathrm{S}_{1}\right)$ was found to have maximum percentage yield $61.1 \%$ drug content $87.92 \%$ and solubility $(0.485 \mathrm{mg} / \mathrm{ml})$, The in-vitro drug release of selected formulation and pure drug was done for 8 hours in various $\mathrm{pH}$ using USP II dissolution test apparatus and results showed that the solid dispersions have higher percentage drug release than pure drug.

\section{Conflict of Interest}

The authors have no conflict of interest, financial or otherwise.

\section{Acknowledgement}

Authors are grateful to the Nano-formulation Research lab, Department of Pharmaceutics, School of Pharmaceutical Education and Research, Jamia Hamdard, New Delhi for providing facilities during this work.

\section{References}

1. Savjani KT, Gajjar AK, Savjani JK. Drug solubility: importance and enhancement techniques. ISRN Pharm 2012; 2012: 195727.

2. Vimalson DC. Techniques to enhance solubility of hydrophobic drugs: an overview. Asian J Pharm 2016; 10: 27.

3. Altman R, Bosch B, Brune K, et al. Advances in NSAID development: evolution of diclofenac products using pharmaceutical technology. Drugs 2015; 75: 859-77.

4. Monographs on diclofenac. 1996. Indian Pharmacopoeia, The Indian pharmacopoeia commission Ghaziabad on behalf of government of India ministry of health \& family welfare, Vol 1: 697-698.

5. Ali MS, Choudhary V. Solubility Enhancement Methods with Importance of Hydrotropy. J Drug Deliv Ther 2012; 2: 96-101.

6. Beig A, Lindley D, Miller JM, et al. Hydrotropic solubilization of lipophilic drugs for oral delivery: The effects of urea and nicotinamide on carbamazepine solubility-permeability interplay. Front Pharmacol 2016; 7: 1-8.

7. Singh MC, Sayyad AB, Sawant SD. Review on various techniques of solubility enhancement of poorly soluble drugs with special emphasis on solid dispersion. J Pharm Res 2010; 3: 2494-2501.

8. Kim SJ, Lee HK, Na YG, et al. A novel composition of ticagrelor by solid dispersion technique for increasing solubility and intestinal permeability. Int J Pharm 2019; 555: 11-18.

9. Varshney HM, Chatterjee A. Solubility enhancement of poorly hydrophilic drugs by using different newer techniques: A Review. Int J Ther Appl 2012; 6: 13.

10. Kim JY, Kim S, Papp M, et al. Hydrotropic solubilization of poorly water-soluble drugs. J Pharm Sci 2010; 99: 3953-3965.

11. Lachman and Liberman's, The Theory and Practice of Industrial Pharmacy, CBS Publishers and Distributers New Delhi; ed. $4^{\text {th }}, 2013: 223$.

12. El-Houssieny BM, El-Dein EZ, El-Messiry HM. Enhancement of solubility of dexibuprofen applying mixed hydrotropic solubilization technique. Drug Discov Ther 2014; 8: 178-184.

13. Patil RM, Maniyar AH, Kale MT, et al. Solid dispersion: strategy to enhance solubility. Chem inform 2012; 43: 66-73.

14. Vemula VR, Lagishetty V, Lingala S. Solubility enhancement techniques. IJPSRR 2010; 5: 41-51.

15. Brahmankar DM, Jaiswal SB. Biopharmaceutics and pharmacokinetic -A treatise, Vallabh Prakashan, New Delhi; ed. $3^{\text {rd }}$, 2016: 351-352.

16. Madan JR, Pawar KT, Dua K. Solubility enhancement studies on lurasidone hydrochloride using mixed hydrotropy. Int J Pharm Investig 2015; 5: 114.

17. Jafari E. Preparation, characterization and dissolution of solid dispersion of diclofenac sodium using Eudragit E-100. J Appl Pharm Sci 2013; 3: 167.

18. Vasconcelos T, Sarmento B, Costa P. Solid dispersions as strategy to improve oral bioavailability of poor water soluble drugs. Drug discov today 2007; 12: 1068-1075.

19. Baghel S, Cathcart H, O'Reilly NJ. Polymeric amorphous solid dispersions: a review of amorphization, crystallization, stabilization, solidstate characterization, and aqueous solubilization of biopharmaceutical classification system class II drugs. J Pharm Sci 2016; 105: 2527-2544.

20. Serajuddin AT. Solid dispersion of poorly watersoluble drugs: Early promises, subsequent problems, and recent breakthroughs. J Pharm Sci 1999; 88: 1058-66.

21. Singh S, Baghel RS, Yadav L. A review on solid dispersion. Int J Pharm Life Sci 2011; 2: 1-18.

22. Das A, Nayak AK, Mohanty B, et al. Solubility and 
Dissolution Enhancement of Etoricoxib by Solid Dispersion Technique Using Sugar Carriers. ISRN Pharm 2011; 2011: 1-8.

23. Leuner C, Dressman J. Improving drug solubility for oral delivery using solid dispersions. Eur $\mathbf{J}$ Pharm Biopharm 2000; 50: 47-60.

24. Patil AN, Shinkar DM, Saudagar RB. Review article: solubility enhancement by solid dispersion. Int J Curr Pharm Res 2017; 9: 15-18.

25. Monographs on diclofenac. 2014. Indian Pharmacopoeia, The Indian pharmacopoeia commission Ghaziabad. On behalf of government of India ministry of health \& family welfare, $\mathrm{Vol} 2$; 1550-1551.

26. Shah VP, Amidon GL, GL Amidon. A theoretical basis for a biopharmaceutic drug classification:

The correlation of in vitro drug product dissolution and in vivo bioavailability. Pharm Res 1995; 12: 413-420.

27. Vippagunta SR, Maul KA, Tallavajhala S, et al. Solid-state characterization of nifedipine solid dispersions. Int J Pharm 2002; 236: 111-123.

28. Allawadi D, Singh N, Singh S, et al. Solid dispersions: a review on drug delivery system and solubility enhancement. Int J Pharm Sci Res 2014; 45: 2094-2105.

29. Tripathi KD. Essential of medical pharmacology, Jaypee brother's medical Publishers, New Delhi; ed. $7^{\text {th }} 2013 ; 204$.

30. Pubchem; NIH: U.S national library of medicine, national center for biotechnology information.

31. Zhang L, Alfano J, Race D, Davé RN. Zero-order release of poorly water-soluble drug from polymeric films made via aqueous slurry casting. Eur J Pharm Sci 2018; 117: 245-54.

32. Latif R. Zero-order release profile of metoclopramide hydrochloride sublingual tablet formulation. Pharm Dev Technol 2013; 18: 13721378.

33. Malipeddi VR, Dua K, Awasthi R. Development and characterization of solid dispersionmicrosphere controlled release system for poorly water-soluble drug. Drug Deliv Transl Res [Internet] 2016; 6: 540-550.

34. Vijaya SG, Mishra DN. Preparation and evaluation of solid dispersion of meloxicam with skimmed milk. Yakugaku Zasshi 2006; 126: 93-97.

35. Li DX, Jang KY, Kang W, et al. Enhanced solubility and bioavailability of sibutramine base by solid dispersion system with aqueous medium. Biol Pharm Bull 2010; 33: 279-284.

36. Setyawan D, Dewi MY, Isadiartuti D. Ternary solid dispersion to improve solubility and dissolution of meloxicam. J Basic Clin Physiol Pharmacol 2020; 30: $1-8$.

37. Awasthi R, Madan J, Kamate V, et al. Improving the solubility of nevirapine using a hydrotropyand mixed hydrotropy based solid dispersion approach. Polym Med 2017; 2: 83-90.

This manuscript was peer-reviewed

Mode of Review: Single-blinded

Academic Editor: Dr. M.A. Jahangir

Copyright: (02021 Yadav VK, et al. This article is distributed under the terms of the Creative Commons Attribution 4.0 International License (http://creativecommons.org/licenses/by/4.0/), which permits unrestricted use, distribution, and reproduction in any medium, provided you give appropriate credit to the original author(s) and the source, provide a link to the Creative Commons license, and indicate if changes were made.

(cc) $\mathrm{EY}$ 